When citing, please quote published version:

Cohen, S.A. (2013). Leisure, identities and personal growth. In S. Elkington \& S. Gammon (Eds.) Contemporary Perspectives in Leisure: Meanings, Motives and Lifelong Learning. London: Routledge. (In press)

\title{
Leisure, identities and personal growth
}

\author{
Dr Scott A. Cohen \\ School of Hospitality and Tourism Management \\ University of Surrey, UK
}

\section{Introduction}

Leisure studies have a long history of associating leisure practices and the meanings of leisure with notions of personal growth and self-development. This association is bound up with questions of personal identity and relies on the possibility that we have a stable personal self that we can develop. The prospect of a stable personal self is a distinguishing feature of modernity, and there is now substantial literature from a postmodern perspective suggesting that identities are instead fragmented and transitory. This raises a fundamental tension. If identities are transitory, how can we develop them? And what are the repercussions of this for personal growth through leisure practices? These questions have important implications for the meanings of leisure.

In this chapter I attempt to unpack some of these issues. I begin by discussing personal identities in the context of modernity, drawing out how the challenge of developing a coherent sense of personal identity became a defining feature of the late modern period in the Western world. The discussion leads us to how leisure is implicated in modern developmental approaches to self, particularly through concepts such as 'serious leisure' (Stebbins 1982) and 'flow experience' (Csikszentmihalyi 1990). My focus then turns to a divergent postmodern perspective that argues that there is no core self and we instead exist in a world characterized by increasingly fragmented identities. A postmodern perspective argues that the concept of a stable personal identity that we might develop has been a historical social construction. Such a view has little time for notions of personal growth through leisure.

I then turn to how the social sciences have begun to see a middle ground between postmodern 'discourse determinism' (Wearing \& Wearing 2001) on the one hand and an essentialized 
notion of self on the other. Such a view allows for a re-examination of how we might attempt building a reflective sense of personal identity out of embodied everyday practice. The chapter concludes by reflecting on how positive experiences of leisure, rather than necessarily being viewed as disparate or episodic, may instead constitute a lifestyle in which the accumulation of personally enriching leisure practices engenders perceptions of selfdevelopment and growth. It is through this perspective that there may be some reconciliation of modern and postmodern stances on personal identity and scope for assigning value to the importance of subjective lived experience.

\section{Identities in modernity}

Self and identity are vast and complicated concepts that are contested within the social sciences. Seigel (2005, p. 3) observes that 'few ideas are both as weighty and slippery as the notion of self', and this is evidenced in that over 30,000 publications on self and identity emerged in social psychology alone (excluding related work in sociology and anthropology) in the 80s and 90s (Vaughan \& Hogg 2002). The permeability of self and identity as concepts means they sometimes merge into each other and can be described as co-terminus (Collinson $\&$ Hockey 2007, Seigel 2005). Although distinctions are at times drawn between collective and personal (self) identity, Breathnach (2006, p. 113) reminds us that identities are "neither wholly collective nor individual, but are formed in the interaction between the individual and the subject position available to them'. Hence, identities are constructed through difference, in the recognition of what one is not in relation to others (Hall 1996, Walseth 2006). Consequently, Hall (1996) defines identities as temporary points of attachment to subject positions constructed through discursive practices. While this definition focuses on how identities are discursively constructed, it is important to remember that our personal identity, or sense of self, while being housed in our physical body and including our emotions, is also an individually experienced reflective construction through which we anchor and position ourselves in the social world. As Gergen (1991 p. x) simply puts it, self refers to 'our ways of understanding who we are and what we are about'.

The challenge of developing a coherent sense of personal identity in the context of an increasing array of life options has been characterized as a defining feature of late modernity in the Western world (Bauman 2000, Giddens 1991). Aligning this phenomenon with the Western world gives due recognition to the fact that the Western self is a 'hyperindividualized entity forged under the authoritarian orientation of Judeo-Christian monotheism' (D'Andrea 2007, p. 112), whereas non-Western understandings of personal identity constructed under different cultural histories have constituted different ways of understanding ourselves in relation to others. Even the word 'self' only first appeared as a noun in the English language at the beginning of the $14^{\text {th }}$ century (Danziger 1997). Burkitt (1991, p. 1) puts it well in stating that the starting point for self as an area of concern in the modern West is the deeply ingrained view of 'human beings as self-contained unitary individuals who carry their uniqueness deep inside themselves, like pearls hidden in their shells' waiting to be found. 
The importance attributed to personal identity in the Western world has been the product of this pervasive meta-narrative of 'self' as an inner source that should be cultivated, alongside a loosening of the structures that previously constituted identities (such as social class, religion, gender and 'race') and a consequent accelerating range of options and opportunities for constructing and exploring selves (for some) under conditions of rapid globalisation (Gergen 1991). A consequence of this social opening and pluralisation of options has been increasingly transitory and disconnected relationships that may contribute to a fragmented sense of personal identity (ibid).

Arising out of these conditions, which Bauman (2000) describes as 'liquid modernity', was a growing tendency amongst Western moderns to use personal identity as an 'anchor' or sensemaking device (Kuentzel 2000). Making sense of one's identity thus became understood as a reflexive project of maintaining a coherent narrative or biographical 'story' about the development of one's self (Giddens 1991). Hence the idea of self-development, both reflexively organized and internally referential (ibid), emerges from the project of the self in late modernity. As McAdams (1997, p. 62) summarizes: '[m]odern men and women routinely adopt a developmental rhetoric in making sense of their own lives'. From this perspective, we can see notions of self-development and personal growth as fundamentally linked to the modern quest for identity. Consequently, humanist ideals in developmental psychology of self-actualisation and self-fulfilment (e.g. Maslow 1971, Rogers 1969), which suggest that individual (selves) may develop or grow, need to be understood as products of this late modern meta-narrative of identity seeking.

Leisure is centrally implicated in this meta-narrative; Kuentzel (2000) observes that the notion of self-development through the medium of leisure has served as a theoretical starting point in traditional leisure studies. Indeed, mastery, competence and learning through leisure activities have been common themes in leisure research that takes a developmental approach; such research examines the personal benefits that may accrue to individuals through leisure practices, for example through Stebbins' (1982) 'serious leisure' framework and in applications of Csikszentmihalyi's (1990) 'flow theory' (e.g. Priest \& Bunting 1993, Stein et al. 1995). A discourse of self-development is clearly evident in Stebbins' (1982, p. 267) concept of serious leisure: '[i]f leisure is to become, for many, an improvement over work as a way of finding personal fulfilment, identity enhancement, self-expression, and the like, then people must be careful to adopt those forms returning the greatest payoff'. Likewise, Csikszentmihalyi (1990, p. 41) contended that 'following a flow experience, the organization of the self is more complex than it had been before'. Thus he (ibid) implies that overcoming challenges through the repetition of flow activity results not just in heightened states of being, but a route towards self-fulfilment. Such perspectives, in which leisure is imbued with challenge, purpose, goals and growth have been central to conceptions of leisure that position it as much more than just frivolous play or free time.

If we accept, however, that humanist concepts of self-development and personal growth are part and parcel of the meta-narrative of identity seeking in late modernity, then implicitly these concepts are subject to the same critiques levelled by postmodern theory at notions of a unified or core self. It is to this postmodern fragmentation that I now turn. 


\section{Postmodern fragmentation of identities}

'In the postmodern world there is no individual essence to which one remains true or committed. One's identity is continuously emergent, re-formed, and redirected as one moves through the sea of ever-changing relationships. In the case of 'Who am I?' it is a teeming world of provisional possibilities.' (Gergen 1991, p. 139)

Gergen's words capture well the possibilities associated with a postmodern perspective. Yet the instability associated with this sea of change, as compared to fixity, also alludes to potential anxieties deriving from our (selves) being set adrift. As aspects of our personal identities become more a matter of choice than social ascription, many individuals are forced to negotiate their sense of self among an increasing range of persons, forms of relationships, options and opportunities that can be transitory, fragmented and unstable (Cote \& Levine 2002, Gergen 1991, Giddens 1991). This process is being accelerated with the introduction of technologies that make local face-to-face interactions rarer and contribute further to the fragmentation of social interactions. The result of this pluralisation of options and growth in incoherent and disconnected relationships is the supposed fragmentation of our sense of self (Gergen 1991, Giddens 1991).

In tension with a modernist view of personal identity as unified and actualisable, these processes of societal change in contrast suggest the emergence of a cacophony of relational selves, as the centre fails to hold and personal identity slides from image to image, being presented on the 'whim of the moment' and eschewing substance (Cote \& Levine 2002). Bauman's (1996, p. 18) words encapsulate well these divergent perspectives between identity in modernity and postmodernity: "if the modern "problem of identity" was how to construct an identity and keep it solid and stable, the postmodern "problem of identity" is primarily how to avoid fixation and keep options open'. Thus the concept of a core self that 'develops and matures through life's experiences carries little currency in postmodern theory' (Kuentzel 2000, p. 88). This viewpoint has little time for ideas of self-development and personal growth, including modern associations between development and the meaning of leisure, when that which is to be developed or grown is deemed fractured or unstable to begin with.

The postmodern deconstruction of a core personal identity was taken to its farthest reach by Foucault (1988), who radically argued that the entire notion of a stable reflective self was a historical social construction. Through linguistic practice, or what Foucault (ibid) referred to as 'technologies of the self', individuals were encouraged to learn socially condoned procedures for systematically reflecting upon their own thoughts, feelings and behaviours (Danziger 1997). The Catholic practice of confession, keeping a diary and the increase in modern literary productions preoccupied with the idea of an inner core self were given as examples of how these 'technologies of the self' train us to reflect on the 'I' and the 'me' as a unique internal essence (Cohen \& Taylor 1992, Foucault 1988). Underpinning Foucauldian understandings of reflective identity as linguistically constructed is the observation that technologies of self vary significantly across different cultures where these practices may be instituted and understood in different ways. Thus the modern notion that our core self could 
be slow and arduously discovered (Cohen \& Taylor 1992) was jettisoned under the pretext that the idea of 'self' is culturally contingent.

Although seeming nihilistic, a postmodern perspective on identity is not intended as a negative outlook. Quite to the contrary, the idea is 'the more selves the merrier' (McAdams 1997, p. 51). Thus we come back to Gergen's (1991) words on the 'possibilities' opened up by a postmodern perspective, as Seigel (2005, p. 4) attempts to explain the postmodern motivation for deconstructing the idea of a core self: 'they did so on behalf of a vision of transcendent freedom that overwhelms the more modest visions of personal integration and regulated autonomy projected by the ideas and practices they sought to supersede'. Whilst modern and postmodern perspectives on personal identity represent sharply contrasting views, two important questions can and should be asked here: 1) Is there a functional middle ground between these perspectives?; and 2) What is the significance of the subjective lived experiences of individuals who use leisure as a field for personal growth? I address these questions in turn in the following sections.

\section{A performative embodied middle ground}

Despite a postmodern understanding of personal identities as multiple and fluid, McAdams (1997, p 47) suggests 'one should not dismiss the possibility that selves nonetheless retain a certain degree of unity and coherence'. Framing the issue in terms of a continuum, Holland (1997) proposes that two poles can be seen in contemporary academic discussions of personal identity, with the range including an extreme 'essentialist' view that fails to take account of the positioning power of discourse (i.e. a modernist perspective) and a completely contrasting ephemeral (i.e. postmodern) position that denies agency. Holland's (ibid) critique of the latter pole seeks to discredit the Foucauldian (1988) view that language and culture have total power to 'set strict limits to what people are able to think, or deeming consciousness to be so fully constituted by social and cultural relations that mental life becomes a kind of precipitate of collective existence, losing its independence' (Seigel 2005, p. 21). Levels of autonomy associated with leisure, in relation to the extent that leisure practices are socially constructed (and controlled) by discourse, can also be conceived in these terms.

In contrast to these polarized perspectives, it has been suggested that the difficulty in accurately theorising the relationship between the individual and the power of discourse has stemmed from self and society having been dichotomized in the literature in the first place (Burkitt 1991). Butler's (1990) work on the performativity of gender offers a perspective on constructing personal identities that may help to bridge the gap between the determining power of discourse and the agency of embodied selves (Bell 2008). In applying performativity to identities, Bell (2008, p.174) explains that 'performativity has come to mean that we perform multiple and shifting identities in history, language, and material embodiments.' Butler (1990, p.277) observes that the constitution of personal identity is an embodied performance that is processual, wherein individuals are always 'on the stage' and 'within the terms of the performance', however 'just as a script may be enacted in various ways, and just 
as the play requires both text and interpretation' so can individuals 'expand the cultural field bodily through subversive performances of various kinds' (ibid, p.282).

Therefore, while all performances of personal identity are citations, or enacted ways of doing, for instance, gender, ethnicity, class, age and abilities, selves are also performative in that they are negotiated in and through a process of becoming (Bell 2008). The theatrical metaphor of 'kinesis', which builds from Goffman's (1959) dramaturgical performance approach to social interaction, offers insight into the performative nature of constituting personal identities as a process of 'breaking and remaking' in which performances not only mirror and sustain normative boundaries but can also subvert and transgress them (Bell 2008, p.13). Such notions of performance and performativities are increasingly applied within contemporary leisure theory (e.g. Gilchrist \& Ravenscroft 2013, Waitt \& Clifton 2013), as illustrative of how spaces and discourses are produced, reproduced, resisted and transformed.

A performative perspective denies the existence of a core personal identity, while recognising that individuals have the power to perform multiple and shifting selves (ibid). Thus, personal identities are not fixed givens, but are always in process, with individuals having some power in the production and reproduction of their sense of personal identity. Stemming from this perspective, social science research that views personal identities as situational and performed in everyday embodied practice has gained speed.

Allied to this view is the recognition that postmodernity 'is a transitional phenomenon, rather than a novel, well-integrated and permanent cultural system' (Cohen 1995, p. 24). There is still substantial debate in sociology as to whether Western society can be described by an 'amalgamation' of the characteristics said to form the condition of postmodernity or whether it is still in the throes of late modernity (Sharpley 2003). Of course, it is more likely that Western society is somewhere between the two, as while aspects of the world might be described as postmodern, it would be inaccurate to assume that all individuals perceive the world through a postmodern lens (Gergen 1991). Thus, instead of ceasing to believe in one's self as an autonomous agent, wherein one is 'dictated by communal consciousness', many individuals still seek to form 'a patterned collection of social practices that constitute a sense of continuity and stability' (Cote \& Levine 2002, p. 28). It is still common to try to actively construct a coherent sense of personal identity through narratives 'rooted in the human propensity to remember and project' (Seigel 2005, p. 653), and as such notions of selfdevelopment and personal growth do remain highly relevant when examined in the context of subjective lived experience.

\section{Leisure as a field for personal growth}

Much of the preceding discussion has focused on personal identity and development more generally, drawing mainly from social psychology and sociology. It is here that I now hone in on the prospects for, and potential benefits from, perceived self-development and personal growth through the vehicle of leisure. I begin with a brief Western historical perspective on the interconnections between leisure and self-development. 
Aristotle's classical leisure ideal provided the original theoretical groundwork for leisure studies (Pieper 1952). With its roots 2,300 years ago in Greek civilisation, the classical leisure ideal is a Occidentalocentric or Eurocentric concept that advocates leisure as a way of living which is characterized by a sense of freedom, learning for its own sake and as being undertaken for self-development (de Grazia, 1962). Goodale and Godbey (1988, p.38) noted these early linkages between leisure, freedom and knowledge: 'importantly, is the link between learning and the leisure ideal held out by the early Greek philosophers...[k]nowledge has always been related to freedom, and freedom has always been related to leisure.' Despite the classical leisure ideal being overwhelmed by the rise of the Roman Empire and Calvin's Protestant work ethic (and for the sake of this argument ignoring that ancient Greek citizens commonly kept slaves whose work freed up their owners' leisure time), carrying on from ancient Greece into modern leisure discourse were these ideals of freedom, intrinsic motivation, learning and self-development through leisure (Goodale \& Godbey 1988, Neulinger 1981). Thus, leisure has been associated with a Western meta-narrative of self-development and personal growth for quite some time.

Whilst modern leisure theorists give due recognition to the blurring between intrinsic and extrinsic motivation (Kelly 1996) and recognize that freedom in leisure is perceived rather than absolute (Neulinger 1981), the narrative of gaining self-insight and fulfilment through leisure, and particularly through personally challenging and/or 'adventurous' activities, is common in contemporary discourse. Thus, there is a considerable body of literature within leisure and recreation scholarship positing that self-insight or knowledge can be gained through the negotiation of 'risky situations' (e.g. Walle 1997, Weber 2001), as individuals may seek subjectively challenging experiences that provide opportunities for perceived learning and self-testing. This has been exhibited in the growth of adventure recreation activities (Ewert \& Jamieson 2003), and although much of the theory concerning motivations for engagement in adventure experiences has focused on the notion of seeking risk (e.g. Ewert 1989), alternative explanations suggest self-development through subjective challenge is a primary motivation (Walle 1997, Weber 2001).

This perspective on adventure recreation brings us back to developmental views on leisure more generally, which at least partially rest on humanist ideals of self-actualisation (e.g. Maslow 1971) that claim we should strive to develop and fulfil our potential. Moments of self-actualisation were described by Maslow (ibid, p. 50) as 'peak experiences', paralleling Csikszentmihalyi's (1990) description of flow experiences, characterized as a heightened internal state achieved through challenging situations. These experiences have been represented as experiential states through which individuals may temporarily escape selfconsciousness and re-emerge with a 'stronger' sense of self (ibid). Flow experiences typically accompany activities perceived as intrinsically motivated or freely chosen (Mannell, Zuzanek \& Larson 1988). Ranging from rock climbing to dancing or sculpting, to name but a few leisure examples, Csikszentmihalyi (1990) suggested that nearly any activity that allows for increasing difficulty can lead to flow experiences and a more complex self. In this sense, flow experience has clear synergies with Stebbins' (1982, p. 256) notion of serious leisure, which 
likewise views perseverance and 'significant personal effort' in forms of leisure as potential routes towards enhancing identity and experiencing personal fulfilment.

I will not endeavour here a comprehensive explanation of the reported dimensions of flow experience or the qualities of serious leisure, as my point is not to re-present these concepts in their entirety. Rather I have hoped to demonstrate how flow theory, also called 'optimal experience' (note that optimal denotes 'most favourable'), and the concept of serious leisure have been depicted as vehicles for self-development. Crucially, aspects of personal growth associated with flow experiences through leisure have often taken a back seat to a primary focus on the characteristics of intense individual moments (e.g. Jones, Hollenhorst \& Perna 2003), without enough consideration of the implications of the totality of these moments for both an individual's personal identity and sense of overall subjective well-being. Thus, this brings us back to the central tension that has developed in this chapter - in light of postmodern theory that has deconstructed notions of self-development - are subjective experiences of personal growth through leisure practices of enduring significance?

\section{Concluding thoughts}

The conditions associated with postmodernity have been accompanied by scepticism towards the meta-narrative of self-development. A postmodern perspective casts doubt on the prospects of taking leisure seriously. However, there are some fundamental gaps in the postmodern deconstruction of a core personal identity that suggest leisure practices can be more than just the enjoyable passage of time: indeed, it can be argued that when the value of leisure is assessed as a product of the mind, perceptions of personal growth and development can accrue as a positive benefit for individuals.

It is helpful here to draw on another one of the qualities that Stebbins (1982) attributed to serious leisure: the tendency for adherents of serious leisure practices to perceive a 'career' in their endeavours. Stebbins (ibid, p. 256) describes these experiences as 'anything but evanescent occurrences devoid of social or psychological continuity'. Thus, at least serious leisure practices, when strongly identified with and carried on over time, may lend an element of continuity to one's personal identity. As social relations in late modernity become increasingly fragmented, leisure experiences may therefore be a route through which individuals seek to structure aspects of their sense of self. Such a perspective inter-relates with the importance of lifestyles under conditions of post-Fordism, in which personal identities become increasingly structured through (leisure) consumption practices (Shields 1992, Featherstone 1987). As Giddens (1991, p. 81) went on to suggest: 'lifestyle consumption practices became decisions not only about how to act but who to be'. Hence while 'career' may not be the best analogy for consumption-led leisure lifestyles, Stebbins' (1997, p. 350) later work on the concept of lifestyle is also helpful in suggesting that leisure lifestyles can be comprised of on-going tangible practices, orientations and ways of identifying, constituting 'the basis for a separate, common social identity'. 
Turning back to flow experiences, rather than seeing these as disparate and episodic heightened moments, we might instead take the point of view of how the totality of flow experiences accumulated through a particular leisure lifestyle may contribute to a unique sense of personal identity and well-being on the one hand and a distinct and recognisable social identity on the other (Cohen 2011). My ethnographic research with 'lifestyle travellers' (ibid) is one example of this, as I found that individuals who backpacked for years on end for the most part experienced this leisure lifestyle as a meaningful source of identity, characterized by high personal investment, challenge and the linking of rewarding episodes into an on-going perception of learning and gaining competencies. Furthermore, Wheaton's (2004) work on lifestyle sports is rife with examples of how re-occurring positive leisure experiences are assembled into a lifestyle, through a particular 'assemblage of goods, clothes, practices, experiences, appearance and bodily dispositions' (Featherstone 1987, p. 59). For our present discussion, the important point to tease out is that the on-going performance of embodied leisure practices not only constitute recognisable leisure lifestyles, but may also be a source of stability and well-being for those taking part.

Through adhering to a particular leisure lifestyle, individuals perform a patterned collection of everyday social practices that may give them a sense of continuity. The accumulation of their on-going subjective lived experience may provide perceptions of personal growth and self-development, possibly through a gestalt effect in which positive perceptions of cumulative experience exceed the sum of its parts. Regardless of postmodern perspectives that may try to objectively devalue these possibilities for development, the perceived psychological benefits of enduring involvement with a meaningful activity may remain intact for individuals. This focus on the psychological benefits of positive experience, taken forward recently in a wider discourse of 'positive psychology' (see Fredrickson 2001, Seligman \& Csikszentmihalyi 2000), gives renewed emphasis to the subjective experience of positive emotions and how cumulative experience can affect wellbeing and human flourishing. Consequently, just because identity formation and notions of personal growth may be products of the mind, we cannot and should not discard the value of positive leisure experiences as a vehicle towards personal wellbeing.

\section{References}

Bauman, Z. (1996) From pilgrim to tourist—or a short history of identity. In S. Hall \& P. du Gay (Eds) Questions of cultural identity (pp. 18-36), London: Sage.

Bauman, Z. (2000) Liquid modernity. Cambridge: Polity Press.

Bell, E. (2008) Theories of performance. Los Angeles: Sage. 
Breathnach, T. (2006) Looking for the real me: Locating the self in heritage tourism. Journal of Heritage Tourism, 1(2): 100-120.

Burkitt, I. (1991) Social selves: Theories of the social formation of personality. London: Sage.

Butler, J. (1990) Performative acts and gender constitution: An essay in phenomenology and feminist theory. In S. Case (Ed) Performing Feminisms: Feminist Critical Theory and Theatre (pp. 270-282), Baltimore, MD: Johns Hopkins University Press.

Cohen, E. (1995) Contemporary tourism-Trends and challenges: Sustainable authenticity or contrived post-modernity? In R. Butler \& D. Pearce (Eds) Change in tourism: People, places, processes (pp. 12-29), London: Routledge.

Cohen, S.A. (2011) Lifestyle travellers: Backpacking as a way of life. Annals of Tourism Research, 38(4): 1535-1555.

Cohen, S. \& Taylor, L. (1992) Escape attempts: The theory and practice of resistance to everyday life. London: Routledge.

Collinson, J. A. \& Hockey, J. (2007) 'Working out' identity: Distance runners and the management of disrupted identity. Leisure Studies, 26(4): 381-398.

Cote, J.E. \& Levine, C.G. (2002) Identity formation, agency, and culture: A social psychological synthesis. Mahwah: Lawrence Erlbaum Associates.

Csikszentmihalyi, M. (1990) Flow: The psychology of optimal experience. New York: HarperCollins. 
D'Andrea, A. (2007) Osho international mediation resort (Pune, 2000s): An anthropological analysis of Sannyasin therapies and the Rajneesh legacy. Journal of Humanistic Psychology, 47(1): 91-116.

Danziger, K. (1997) The historical formation of selves. In R. D. Ashmore \& L. Jussim (Eds) Self and identity: Fundamental issues (pp. 137-159), New York: Oxford University.

de Grazia, S. (1962) Of time, work and leisure. New York: The Twentieth Century Fund.

Ewert, A. (1989) Outdoor adventure pursuits: Foundations, models, and theories. Columbus: Publishing Horizons.

Ewert. A. \& Jamieson, L. (2003) Current status and future directions in the adventure tourism industry. In J. Wilks \& S.J. Page (Eds) Managing tourist health and safety in the new millennium (pp. 67-83), Amsterdam: Pergamon.

Featherstone, M. (1987) Lifestyle and consumer culture. Theory, Culture and Society, 4(1): $55-70$.

Foucault, M. (1988) Technologies of the self. In L. Martin, H. Gutman \& P. Hutton (Eds) Technologies of the self: A seminar with Michel Foucault (pp.16-49), London: Tavistock.

Fredrickson, B. L. (2001) The role of positive emotions in positive psychology: The broadenand-build theory of positive emotions. American Psychologist, 56(3): 218-226.

Gergen, K.J. (1991) The saturated self: Dilemmas of identity in contemporary life. USA: Basic-Books.

Giddens, A. (1991) Modernity and self-identity: Self and society in the late modern age. Cambridge: Polity Press. 
Gilchrist, P. \& Ravenscroft, N. (2013) Space hijacking and the anarcho-politics of leisure. Leisure Studies, DOI: 10.1080/02614367.2012.680069.

Goodale, T.L. \& Godbey, G.C. (1988) The evolution of leisure: Historical and philosophical perspectives. State College, PA: Venture.

Goffman, E. (1959) The presentation of self in everyday life. New York: Anchor.

Hall, S. (1996) Introduction: Who needs ‘identity'. In S. Hall \& P. du Gay (Eds) Questions of cultural identity (pp. 1-17), London: Sage Publications.

Jones, C.D., Hollenhorst, S.J. \& Perna, F. (2003) An empirical comparison of the four channel flow model and adventure experience paradigm. Leisure Sciences, 25: 17-31.

Kelly, J. (1996) Leisure. Boston: Allyn and Bacon.

Kuentzel, W.F. (2000) Self-Identity, modernity, and the rational actor in leisure research. Journal of Leisure Research, 32(1): 87-92.

Mannell, R.C., Zuzanek, J. \& Larson, R. (1988) Leisure states and 'flow' experiences: Testing perceived freedom and intrinsic motivation hypotheses. Journal of Leisure Research, 20(4): 289-304.

Maslow, A. (1971) The farther reaches of human nature. Middlesex: Penguin Books.

McAdams, D.P. (1997) The case for unity in the (post)modern self: A modest proposal. In R.D. Ashmore \& L. Jussim (Eds) Self and identity: Fundamental issues (pp.46-78), New York: Oxford University Press.

Neulinger, J. (1981) The psychology of leisure: 2nd Edition. Springfield: Charles C. Thomas.

Pieper, J. (1952) Leisure: The basis of culture. New York: Pantheon Books. 
Priest, S. \& Bunting, C. (1993) Changes in perceived risk and competence during whitewater canoeing, Journal of Applied Recreation Research, 18(4): 265-280.

Rogers, C.R. (1969) Freedom to learn. Columbus: Charles E. Merrill.

Seigel, J. (2005) The idea of the self: Thought and experience in Western Europe since the seventeenth Century. Cambridge: Cambridge University.

Seligman, M.E. \& Csikszentmihayli, M. (2000) Positive Psychology. An introduction. American Psychologist, 55(1): 5-14.

Sharpley, R. (2003) Tourism, tourists and society. Huntingdon: Elm Publications.

Shields, R. (1992) Spaces for the subject of consumption. In: R. Shields (Ed) Lifestyle shopping: The subject of consumption (pp. 1-20), London: Routledge.

Stebbins, R.A. (1982) Serious leisure: A conceptual statement. The Pacific Sociological Review, 25(2): 251-272.

Stebbins, R. A. (1997) Lifestyle as a generic concept in ethnographic research. Quality and Quantity, 31(4): 347-360.

Stein, G.L., Kimiecik, J.C, Daniels, J., \& Jackson, S.A. (1995) Psychological antecedents of flow in recreational sport. Personality and Social Psychology Bulletin, 21(2): 125-135.

Vaughan, G. M. \& Hogg, M. A. (2002) Introduction to social psychology, 3rd edition. Frenches Forest: Pearson Education.

Waitt, G. \& Clifton, D. (2013) 'Stand out, not up': bodyboarders, gendered hierarchies and negotiating the dynamics of pride/shame. Leisure Studies, DOI: 10.1080/02614367.2012.684397. 
Walle, A.H. (1997) Pursuing risk or insight: Marketing adventures. Annals of Tourism Research, 24(2): 265-282.

Walseth, K. (2006) Young Muslim women and sport: The impact of identity work. Leisure Studies, 25(1): 75-94.

Wearing, S. \& Wearing B. (2001) Conceptualizing the selves of tourism. Leisure Studies, 20(2): 143-159.

Weber, K. (2001) Outdoor adventure tourism: A review of research approaches. Annals of Tourism Research, 28(2): 360-377.

Wheaton, B. (2004) Understanding lifestyle sports: Consumption, identity and difference. London: Routledge. 